\title{
Qol Resistance in Sugar Beet Powdery Mildew (Erysiphe betae) in Scandinavia
}

\author{
Thies Marten Heick, ${ }^{1, \dagger}$ Anne Lisbet Hansen, ${ }^{2}$ Annemarie Fejer Justesen, ${ }^{1}$ and Lise Nistrup Jørgensen ${ }^{1}$ \\ ${ }^{1}$ Aarhus University, Flakkebjerg, Department of Agroecology, 4200 Slagelse, Denmark \\ ${ }^{2}$ NBR Nordic Beet Research, Sofiehøj, 4960 Holeby, Denmark
}

Accepted for publication 17 June 2019.

Keywords: quinone outside inhibitors, fungicide resistance, field crops

Powdery mildew caused by Erysiphe betae is one of the major fungal diseases in sugar beet in Denmark and Sweden (Francis et al. 2007; Hansen 2019). Frequent applications of fungicides mitigate the risk of powdery mildew epidemics and, consequently, reduce yield losses conferred by the disease. So far, mixtures of quinone outside inhibitors (QoIs) and triazoles have provided good efficacy against $E$. betae in field trials and common farming practice (Hansen 2019; Karaoglanidis and Karadimos 2006). However, development of fungicide resistance is a real risk, because only a limited number of active ingredients are available for the control of powdery mildew in sugar beet, and several other active ingredients are expected to be banned following reevaluation when the most recent European Union legislation is implemented.

From 2013 to 2018, the efficacy of pyraclostrobin and epoxiconazole on Danish and Swedish sugar beet powdery mildew was tested on sugar beet under semicontrolled conditions, in which sugar beets (cultivar Julietta KWS) were planted in 8-liter buckets and placed outdoors, irrigated, and sheltered from rain. Disease-free sugar beet plants were inoculated with powdery mildew at growth stage 19 , by transferring conidia directly onto the healthy plants by rubbing. The plants were covered with plastic bags for $24 \mathrm{~h}$ to promote infection. The sugar beets were treated with fungicides 1 day after inoculation. Treatments included 0.5 liter/ha of Comet (100 g/liter of pyraclostrobin, BASF A/S) and 0.5 liter/ha of Opus (62.5 g/liter of epoxiconazole, BASF A/S), half the recommended label rate (1 liter/ha), which until now has provided effective control of powdery mildew in sugar beet (Hansen 2019). The trials were set out in a randomized plot design with three replicates and included an uninfected control. Ten powdery mildew populations (five from Denmark and five from Sweden) from farmers' fields treated with QoI or QoI/triazole mixtures were used for the experiment each year.

Symptoms of powdery mildew developed within 10 to 14 days after inoculation on untreated plants. In 2013 to 2016, no symptoms of powdery mildew were observed following fungicide treatments. Two samples in 2017 and one sample in 2018 developed powdery mildew symptoms on plants treated with pyraclostrobin but not on those treated with epoxiconazole. All three samples were from Denmark.
QoI resistance in powdery mildew on sugar beet was reported previously from fields treated with pyraclostrobin or trifloxystrobin in the United States and has been associated with the presence of amino acid substitution G143A in the cytochrome $b$ gene (Bolton and Neher 2014). A total of $43 \mathrm{E}$. betae isolates from three different years were tested following the procedures by Bolton and Neher (2014) to confirm the presence of the G143A mutation in Danish and Swedish E. betae populations. Two out of three isolates in 2015 , two out of 10 isolates in 2017, and 21 out of 30 isolates in 2018 tested positive for the G143A mutation. All isolates came from different fields. Five of the 21 isolates that tested positive for G143A in 2018 also tested positive for the wild-type allele, possibly indicating mixed isolates. In 2018, the E. betae G143A mutation was found in both in Denmark and Sweden. Sequences of both haplotypes have been uploaded to GenBank under accession numbers MK301140 and MK301141. This is the first report of the G143A mutation in E. betae in European populations.

The current finding strongly encourages the adoption of antiresistance strategies that minimize the spread of QoI resistance in sugar beet powdery mildew. Those strategies should be based on integrated pest management measures, including disease monitoring, the use of resistant cultivars, and the use of biological products. A sole reliance on QoI fungicides for sugar beet powdery mildew control should be avoided.

\section{Literature Cited}

Bolton, M. D., and Neher, O. 2014. First report of QOI-insensitive powdery mildew (Erysiphe polygoni) on sugar beet in the United States. Plant Dis. 98:1004.

Francis, S. A., Roden, B. C., Adams, M. J., Weiland, J., and Asher, M. J. 2007. Comparison of ITS sequences from UK and North American sugar-beet powdery mildews and the designation of Erysiphe betae. Mycol. Res. 111: 204-212.

Hansen, A. L. 2019. Bladsvampe - midler og doseringer. Nordic Beet Res. Annu. Rep. 22:32-37. https://www.nordicbeet.nu/nbr-publications/fagligberetning-2018-verksamhetsberaettelse-2018/

Karaoglanidis, G. S., and Karadimos, D. A. 2006. Efficacy of strobilurins and mixtures with DMI fungicides in controlling powdery mildew in field grown sugar beet. Crop Prot. 25:977-983. 